\title{
Construções de duplo objeto em dois dialetos brasileiros
}

\author{
Rerisson Cavalcante* \\ Isis Barros
}

Resumo: Nesse artigo, analisamos o fenômeno de omissão da preposição em complementos dativos em dois dialetos brasileiros: o da comunidade de Helvécia (BA) e o da Zona da Mata (MG). Partimos da constatação de que a omissão da preposição não é um fenômeno homogêneo nos dois dialetos, pois os contextos em que ocorre não são idênticos. Levantamos, então, a hipótese de que essas diferenças resultam de processos morfossintáticos distintos na derivação dessa estrutura. Defendemos que, em Helvécia, ocorre um processo de atribuição alternativa de caso, de modo semelhante ao fenômeno das construções de duplo objeto do inglês. Na Zona da Mata, por outro lado, ocorre um fenômeno diferente do que há em inglês e em Helvécia. A omissão é condicionada pela adjacência da preposição a um elemento que funcione como núcleo $\mathrm{D}^{\circ}$, o que explica porque o apagamento pode ocorrer independente da posição que o complemento ocupa em relação ao verbo e ao complemento direto e porque não pode ocorrer diante de pronomes indefinidos.

Palavras-chave: complementos dativos; português brasileiro; atribuição de caso; preposições.

Abstract: In this paper we analyze the phenomenon of omission of the preposition in dative complements in two Brazilian dialects: the dialects of Helvécia (state of Bahia-Brazil) and Zona da Mata (state of Minas Gerais-Brazil). The main hypothesis of this study is that the omission of the preposition is not a homogeneous phenomenon in both dialects, but it is the result of different syntactic processes. In Helvécia, there is an alternative process of Case assignments, which is similar to the phenomenon of double object constructions in English. On the other hand, in Zona da Mata, a different phenomenon takes place. The omission is conditioned by the adjacent preposition, an element that functions as $\mathrm{D}^{\circ}$ head, which explains why the deletion can occur regardless of the position in which the dative complement is and why it can not occur before quantifiers and indefinite pronouns.

Keywords: dative complements; Brazilian Portuguese; Case assignment; prepositions.

\section{Introdução}

A proposta desse artigo é analisar o(s) processo(s) que desencadeia(m) a omissão da preposição que introduz complementos dativos (tradicionalmente conhecidos por objetos indiretos de verbos bitransitivos) em dois dialetos do português

\footnotetext{
* Mestre em Letras pela UFBA. Doutorando em Semiótica e Linguística Geral pela FFLCH/USP. Bolsista FAPESP (processo número 2008/00073-0).

Graduada em Letras Vernáculas pela UNIME. Mestranda em Letras pelo PPGLL/UFBA. Bolsista CNPq.
} 
brasileiro (PB): o dialeto da região da Zona da Mata de Minas Gerais e o dialeto da comunidade de Helvécia (município de Nova Viçosa), Bahia. ${ }^{1}$

A hipótese principal do trabalho é que a omissão da preposição não é um fenômeno homogêneo nos dois dialetos, mas é resultado de processos sintáticos distintos.

Segundo a tradição gramatical, a realização canônica de um complemento dativo em português é através de um sintagma nominal (doravante DP ou NP) introduzido pela preposição $a$ (cf. (1a)) ou através de pronomes clíticos como me, te e lhe (cf. (1b)).

(1) a. Ela deu um presente ao filho.

b. Ela me/te/lhe um presente.

No entanto, vários estudos têm apontado que o PB vem passado por um já avançado processo de mudança na realização dos complementos dativos (cf. Torres Morais \& Berlinck, 2006), especialmente os de terceira pessoa. O processo é caracterizado pela: (i) progressiva substituição da preposição a por para (cf. (2a)); (ii) e perda do pronome clítico $l h e^{2}$, substituído pelo pronome forte ele/ela, introduzido por uma preposição (cf. (2b)).

(2) a. Ele deu flores para a namorada.

b. Ele deu flores para ela.

Além desses processos de mudança, ainda pode ser registrado um outro tipo de realização dos complementos dativos, com abrangência mais restrita dentro do PB. Em pelo menos dois dialetos, o da Zona da Mata de Minas Gerais (cf. Scher, 1996) e o da

\footnotetext{
${ }^{1}$ Para mais informações acerca dessas regiões, o leitor pode consultar Scher (1996) sobre a Zona da Mata e Baxter, Lucchesi \& Ribeiro (2009) sobre a comunidade de Helvécia.

${ }^{2}$ Em alguns dialetos, o pronome lhe é usado na função de complemento direto (ou mesmo indireto) de segunda pessoa do singular, relacionado ao pronome você, numa espécie de alternância com o te.
}

(i) Eu lhe/te vi ontem.

(ii) Eu lhe/te disse para não sair de casa. 
comunidade afro-brasileira de Helvécia ${ }^{3}$, Bahia (cf. Barros, 2008), os dativos podem opcionalmente dispensar a presença da preposição, como mostram os exemplos (3) e (4).

\section{Zona da Mata de Minas Gerais}

(3) Eu dei o rapaz o livro.

(Scher, 1996: 12)

Helvécia, Bahia

(4) Quando chegou a hora, deu o japonês vinte mil. (Barros, 2008)

Esse artigo analisa as propriedades dessas construções de acordo com o quadro teórico do programa minimalista (cf. Chomsky, 1995, 2000) e da morfologia distribuída (cf. Halle \& Marantz, 1993). Os dados utilizados na pesquisa são oriundos de duas fontes:

(i) para o dialeto da Zona da Mata, dados de intuição, ou seja, de julgamentos de aceitabilidade de sentenças, por parte de falantes nativos, de acordo com a metodologia amplamente utilizada nos trabalhos de sintaxe formal (cf. Chomsky 1965 e seguintes), registrados no trabalho de Scher (1996) sobre dativos não-preposicionado no dialeto mineiro; dados adicionais de intuição por parte de falantes mineiros foram retirados de Cavalcante (2009).

(ii) para Helvécia, devido à impossibilidade do acesso a julgamentos de aceitabilidade por parte dos falantes do dialeto, recorremos a dados do corpus do projeto

\footnotetext{
${ }^{3}$ Discutindo as hipóteses sobre as origens das mudanças estruturais do português brasileiro, Lucchesi \& Mello (2009) defendem que a omissão da preposição em dativos deve ser considerada um caso de reestruturação original da estrutura gramatical do português, incompatível com a hipótese da deriva secular, mas em conformidade com o previsto em casos de transmissão linguística irregular.

A proposta dos autores, entretanto, depende de um pressuposto não explicitado quanto ao status estrutural da omissão da preposição. Se for simplesmente um exemplo de perda do marcador de Caso (i.e., da preposição), a omissão pode ser vista como mais compatível com a hipótese da deriva do que com a transmissão linguística irregular, por ser um exemplo de enfraquecimento e queda da morfologia, contrariando, assim, a proposta de Lucchesi \& Mello (2009).

Neste artigo, entretanto, mostramos que, tanto no dialeto de Helvécia quanto no da Zona da Mata, a omissão da preposição é sintaticamente condicionada, não podendo ser considerada um simples caso de perda de morfologia. A análise esboçada aqui, dessa forma, fornece evidência teórica adicional para a ideia de Lucchesi \& Mello de que os dativos não-preposicionados favorecem a hipótese da transmissão linguística irregular. Para uma discussão mais detalhada dessa questão, vide Cavalcante (em preparação).
} 
Vertentes do Português Popular do Estado da Bahia, coordenado pelo professor Dante Lucchesi (cf. Lucchesi, Baxter \& Ribeiro (2009)), documentados em Barros (2008) e em Lucchei \& Melo (2009).

O confronto dos dados dos trabalhos descritivos de Scher (1996) sobre a Zona da Mata e de Barros (2008) e Lucchesi \& Mello (2009) sobre Helvécia revela que o fenômeno de omissão da preposição não tem comportamento homogêneo nos dois dialetos, mas apresenta condicionamentos morfossintáticos distintos, como apontado por Cavalcante (2009) e Cavalcante \& Barros (2009).

Nossa análise defende que, em Helvécia, a omissão é resultado de um processo de atribuição diferenciada de Caso abstrato, como consequência da ausência da preposição na derivação sintática (de modo semelhante ao que ocorre nas bem estudadas construções de duplo objeto de línguas como o inglês), ao passo que, no dialeto mineiro, ocorre um processo (morfo-)sintático de fusão entre a preposição (presente na derivação) e o determinante, o que pressupõe a própria presença da preposição na derivação, do modo semelhante ao movimento V-to-T de línguas românicas.

O artigo está organizado da seguinte forma: na seção 2, revisamos as características do fenômeno de duplo objeto no inglês e a análise clássica de Larson (1988) sobre as construções bitransitivas e a alternância dativa; na seção 3, apresentamos as características da omissão da preposição no dialeto da Zona da Mata mineira, conforme descrito por Scher (1996) e Armelin (2008), e propomos uma nova generalização sobre os dados; na seção 4, apresentamos as características da omissão da preposição no dialeto de Helvécia; na seção 5, apresentamos nossa proposta de análise; na seção 6, encerramos o texto com uma conclusão.

\section{As double object constructions do inglês}

Antes de analisarmos as características da omissão da preposição em Helvécia e na Zona da Mata, faremos uma breve revisão das propriedades do fenômeno de duplo objeto do inglês, em que um complemento dativo também pode ocorrer sem a realização da preposição. Não é nosso objetivo apresentar aqui uma revisão sistemática da literatura sobre o tema, algo que estaria além das limitações deste artigo, mas apontar as 
principais propriedades das construções de duplo objeto que são identificadas na literatura. Para uma revisão mais detalhada do tema, remetemos os leitores a Scher (1996) e Torres Morais (2007).

Pesquisas sobre o tema apontam as seguintes características principais para o fenômeno da omissão da preposição de dativos do inglês:

I. A omissão ocorre unicamente com a ordem [V DP $\left.\mathrm{DAT}_{\mathrm{DP}} \mathrm{DP}_{\mathrm{TEMA}}\right]$, em que há adjacência estrita entre o complemento dativo e o verbo (cf. (5a)). A ausência da preposição é agramatical na ordem [V DP $\left.\mathrm{V}_{\mathrm{TEMA}} \mathrm{DP}_{\mathrm{DAT}}\right]$, quando o complemento direto (tema) rompe a adjacência (cf. (5b)) entre o verbo e o dativo. Acrescente-se ainda que, na ordem [V DP $\left.\mathrm{DAT}_{\mathrm{DP}} \mathrm{DP}_{\mathrm{TEMA}}\right]$, a preposição não apenas pode, mas deve ser omitida. $\mathrm{A}$ sua presença é marginal ou inaceitável.

(5) a. I gave Mary a book.

b. I gave a book *(to) Mary.

A relação entre a ordem dos complementos em relação ao verbo e a presença/ausência da preposição aponta para a probabilidade de que a omissão esteja diretamente relacionada à inversão dativa e que, portanto, inversão e omissão sejam consequências de um mesmo fenômeno mais básico.

II. O complemento dativo pode sofrer passivização, sendo alçado para a posição de sujeito em sentenças passivas (cf. (6a)), o que não ocorre em línguas que não possuem construções de duplo objeto, como as línguas românicas (cf. (6b)).

(6) a. Mary was given a book.

b. * Ela foi dado/dada um livro.

Por outro lado, quando é o complemento direto (tema) a ser alçado para a posição de sujeito, o dativo não pode ocorrer sem preposição, como mostra o exemplo em (7).

(7) A book was given *(to) Mary. 
Esses fatos parecem apontar que a ausência da preposição provoca (ou decorre de) uma alteração no status categorial do complemento, que deixa de funcionar como um PP com Caso oblíquo, e passa a se comportar como um DP com Caso acusativo. Em construções passivas, como em (6a) e (7), em que o Caso acusativo não está disponível, o dativo precisaria receber Caso de outro elemento. Os únicos Casos disponíveis para o licenciamento do dativo seriam o nominativo (atribuído por T) ou o oblíquo (atribuído pela preposição). Daí decorreria a complementariedade entre o alçamento do DP dativo e a presença da preposição: quando o complemento direto é o elemento promovido a sujeito, ele recebe o Caso nominativo (cf. (6a)), fazendo com que a única alternativa de licenciamento do DP dativo seja através da preposição. Isso explicaria a agramaticalidade de (7) na ausência da preposição: não há nenhum Caso estrutural disponível para o complemento dativo.

Essas características parecem apontar que as construções de duplo objeto, em inglês, não decorrem apenas de um processo de omissão fonética/fonológica do item lexical, mas são um fenômeno sintaticamente condicionado e, por hipótese, relacionado a um processo alternativo de atribuição de caso ao complemento dativo. Na literatura sobre o tema, é possível encontrar diversas implementações técnicas dessa intuição. Nesse artigo, porém, não entraremos no mérito da comparação ou avaliação das várias análises existentes. Para os propósitos do trabalho, são suficientes a delimitação das características gerais de que a análise deve explicar e a apresentação das linhas gerais do trabalho clássico de Larson (1988) sobre o tema.

Larson (1988) propõe que, nas construções de duplo objeto, ocorre, internamente ao VP, um processo semelhante ao de passivização no nível da sentença. Na ausência da preposição atribuidora de Caso oblíquo/dativo, o NP/DP dativo se moveria para o especificador do VP para receber Caso (acusativo), como na representação em (8), com posterior movimento do verbo para a posição de $\mathrm{V}$ mais alta (que corresponde ao $v$ zinho em versões mais recentes da análise de VP-shell; cf. Chomsky, 1995). Assim, de acordo com essa análise, a inversão da ordem decorreria exatamente da ausência da preposição na estrutura. 
(8)

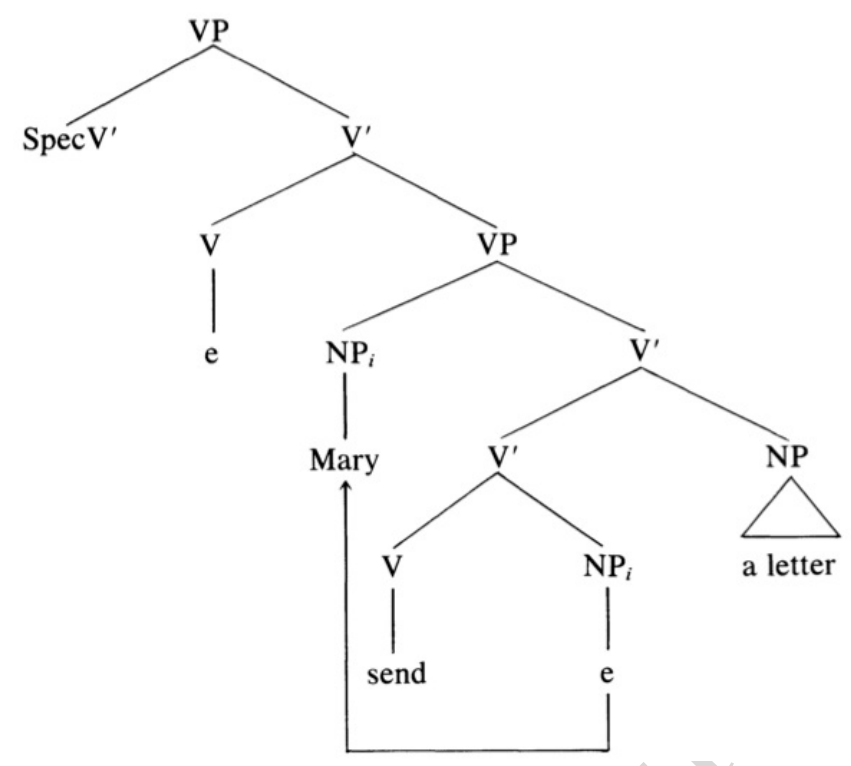

(Larson 1988: 357)

No sistema de Larson (1988), enquanto o dativo recebe Caso estrutural acusativo, o complemento direto receberia Caso inerente do verbo ou, mais especificamente, do V', (formado por $\left.\mathrm{V}+\mathrm{NP}_{\mathrm{DAT}}\right)$.

Deixando de lado, por ora, a implementação técnica da análise, essas são as duas propriedades que nos interessam mais diretamente aqui: (i) a adjacência obrigatória do complemento dativo ao verbo e (ii) a possibilidade de passivização do dativo.

Nas próximas seções, veremos que a omissão da preposição no dialeto de Helvécia apresenta características semelhantes ao fenômeno de duplo objeto do inglês, ao contrário do que ocorre no dialeto da Zona da Mata.

\section{Dativos sem preposição na Zona da Mata}

Nesta seção, trataremos do processo de omissão da preposição em complementos dativos no dialeto da Zona da Mata mineira a partir da descrição realizada no trabalho de Scher (1996). Segundo a autora, o fenômeno apresenta diferenças significativas em relação às construções de duplo objeto do inglês. A principal diferença está relacionada ao requerimento da adjacência, que não se aplica no dialeto mineiro. Em outras palavras, a preposição pode ser omitida tanto na ordem [V 
$\left.\mathrm{DP}_{\mathrm{DAT}} \mathrm{DP}_{\mathrm{TEMA}}\right]$, como no inglês, quanto na ordem [V $\left.\mathrm{DP}_{\mathrm{TEMA}} \mathrm{DP}_{\mathrm{DAT}}\right]$, o que é impossível em inglês e em quase todas as línguas que apresentam construções de duplo objeto.
(9)
a. Eu dei o rapaz o livro.
b. Eu dei o livro o rapaz.

(Zona da Mata)

(Scher, 1996)

Outra diferença apontada por Scher (1996) é que o dialeto da Zona da Mata não permite o alçamento do complemento dativo para a posição de sujeito da sentença, como mostra o exemplo em (10) (cf. também (6b)). Dessa forma, com relação à passivização, o dialeto mineiro se comporta de modo mais semelhante aos demais dialetos do PB (que não omitem a preposição nem permitem a passivização do dativo) do que ao inglês.
(10) a. * Os meninos foram dados um livro. (Zona da Mata)
b. The students were given a book. (Inglês)

Uma peculiaridade (apontada também por Armelin, 2008) é que o dialeto mineiro permite a ausência da preposição independente do objeto tema ser nulo (cf. (10)), o que não ocorre em inglês.
(11) a. Ele entregou o pai ø.
(Armelin, 2008)

Esse fato, entretanto, provavelmente está ligado à propriedade mais geral de o PB permitir objetos nulos (o que o inglês não permite) do que a propriedades específicas das construções dativas nesse dialeto. ${ }^{4}$

Dados esses fatos, Scher (1996) conclui que a omissão da preposição no dialeto mineiro é qualitativamente diferente do fenômeno de duplo objeto de línguas como o inglês. A autora, então, levanta a hipótese de que, na Zona da Mata, não se verifica um fenômeno sintaticamente condicionado, mas um processo fonético (ou fonético-

\footnotetext{
${ }^{4}$ Note-se, então, que, uma vez que a ausência da preposição, no PB, ocorre independentemente da adjacência do dativo ao verbo, a posição da categoria vazia que corresponde ao objeto direto poderia ser tanto pré-dativo ou pós-dativo.
} 
fonológico) de apagamento da preposição (i.e., algo que ocorreria, provavelmente, em $\mathrm{PF}$ ), como, por exemplo, a crase da preposição com a vogal final do verbo anterior.

Contrariando essa hipótese, Cavalcante (2009) argumenta que a possibilidade de crase não explicaria os casos em que a omissão da preposição se dá na ordem [V $\left.\mathrm{DP}_{\mathrm{TEMA}} \mathrm{DP}_{\mathrm{DAT}}\right]$. Nessa configuração, não há adjacência entre a preposição $a$ e a vogal final do verbo. Uma alternativa para esse problema seria postular que, nesses casos, a crase pode ocorrer por adjacência entre a preposição $a$ e a vogal final do próprio complemento direto, que se interpõe entre o dativo e o verbo. Essa alternativa também deve ser descartada, pois a omissão da preposição também é possível quando o elemento que antecede o dativo finda em consoante, como em (12).

(12) O Marcos deu os livros (a)o pai.

Armelin (2008), na mesma linha de investigação, mas já dentro do quadro da morfologia distribuída (i.e., assumindo um sistema com inserção lexical tardia, póssintática), levanta a hipótese de que, na verdade, haja algum processo (entre a forma morfológica e PF) que bloqueia a inserção da preposição em PF. Armelin (2008), contudo, não apresenta uma formulação técnica da natureza desse processo.

Assumindo a hipótese apresentada por Cavalcante (2009), defendemos que a intuição de Scher (1996) e Armelin (2008) sobre a peculiaridade do dialeto mineiro está essencialmente correta, mas que o condicionamento específico que dispara $o$ apagamento da preposição não é fonético-fonológico ou morfofonológico, mas sintático (ou morfossintático).

Analisando o fenômeno de omissão da preposição em dativos no dialeto mineiro a partir dos dados apresentados por Scher (1996), Cavalcante (2009) aponta que a omissão da preposição é sensível ao tipo de elemento que inicia ou introduz o DP dativo. Por exemplo, a preposição $a$ pode ser omitida diante de artigos, como em (13), e diante de pronomes pessoais, como em (14).

(13) a. A Maria deu (a)o João um livro.

b. A Maria deu um livro (a)o João.

(14) a. O Pedro deu um presente (a) ele.

b. O Pedro deu (a) ele um presente. 

c. O Pedro deu um presente (a) você.
d. O Pedro deu (a) você um presente.

A omissão, entretanto, é impossível diante de outros elementos, como os quantificadores todos, algum, nenhum, ninguém, etc, como mostram os exemplos em (15) e (16).

(15) a. O Marcos deu um presente *(a) todos os seus irmãos.

b. O Marcos deu *(a) todos os seus irmãos um presente.

c. A Maria enviou o seu convite de casamento *(a) alguns de seus

amigos.

d. A Maria enviou *(a) alguns de seus amigos o seu convite de casamento.

(Scher, 1996, p. 41-42)

(16) a. Ele não entregou os livros *(a) nenhum aluno.

b. Ele não entregou *(a) nenhum aluno os livros.

c. Ele não entregou os livros *(a) ninguém.

d. Ele não entregou *(a) ninguém os livros.

A impossibilidade de omissão da preposição com quantificadores foi discutida por Scher (1996), que levantou a hipótese de algum tipo de incompatibilidade semântica estar em jogo. O traço de definitude poderia ser um pré-requisito para a inversão e, portanto, para a omissão da preposição. A impossibilidade de omissão poderia, então, ser resultado de esses dativos serem elementos não-definidos ou, mais especificamente, de serem elementos quantificados.

Note-se, porém, que a interferência de algum traço semântico na possibilidade de queda da preposição é difícil de ser compatibilizada com a hipótese de que a omissão ocorre por um processo simplesmente fonológico. Como um traço semântico poderia afetar (permitindo ou proibindo) um processo de crase entre duas vogais adjacentes?

Cavalcante (2009) defende que essa restrição não está relacionada ao tipo semântico dos quantificadores, mas ao seu status categorial. A omissão é possível diante de artigos e pronomes pessoais, como apontamos. O que há de comum entre 
esses dois tipos de elementos? Cavalcante (2009) chama a atenção para o fato de que, de acordo com a proposta de Longobardi (1994), os pronomes pessoais (como ele, você, etc) são elementos que ocupam a posição D. Os quantificadores, por outro lado, encabeçam uma projeção funcional independente, que não se confunde com D ou DP (mas, antes, o toma como complemento). Isso faz com que artigos e pronomes pessoais formem uma classe natural que exclui os quantificadores.

Cavalcante (2009) e Cavalcante \& Barros (2009) propõem que a omissão da preposição no dialeto mineiro está condicionada à presença de um núcleo $\mathrm{D}^{\mathrm{o}}$ iniciando o complemento dativo e propõem a seguinte generalização.

(17) A omissão da preposição em complementos dativos só é possível diante de um núcleo D.

Se a generalização em (17) estiver correta, temos dados suficientes para considerar que a omissão da preposição no dialeto da Zona da Mata não é um fenômeno de natureza puramente fonética, mas apresenta algum tipo de condicionamento estrutural, embora esse condicionalmente seja de natureza distinta do que age nas construções de duplo objeto do inglês.

Antes de avançarmos na análise, apresentamos, na próxima seção, uma descrição do fenômeno da omissão da preposição no dialeto de Helvécia (Bahia). A partir dessa descrição, apresentaremos uma proposta que dá conta das diferenças entre os dois dialetos.

\section{Dativos em Helvécia}

O fenômeno da omissão da preposição em complementos dativos também é encontrado na comunidade de Helvécia, município de Nova Viçosa, sul da Bahia, conforme já aponta Lucchesi (2001). Diferentemente do processo que ocorre no dialeto mineiro, os dados levantados pela pesquisa de Barros (2008) mostram que em Helvécia esse fenômeno tem características bem mais próximas das construções de objeto duplo do inglês.

Segundo Barros (2008), a omissão da preposição em Helvécia apenas ocorre na ordem [V DP $\left.\mathrm{DAT}_{\mathrm{DP}} \mathrm{DP}_{\mathrm{TEMA}}\right]$, como no inglês (cf. (18)). 
(18) a. Dá o pessoá muita lembrança, minha fia. (Helvécia, Inq-19)

b. Deu Luísa iss'aí pra Luísa prantá.

(Helvécia, Inq-19)

No universo dos dados analisados, não há exemplos de omissão da preposição na ordem [V DP ${ }_{\mathrm{TEMA}} \mathrm{DP}_{\mathrm{DAT}}$ ], em que não há adjacência entre o dativo e o verbo. Ou seja, em Helvécia, diferentemente da Zona da Mata, a omissão da preposição parece estar restrita à ordem em que o dativo ocorre imediatamente após o elemento verbal, de modo semelhante ao que acontece nas construções de duplo objeto do inglês.

Barros (2008), contudo, não inclui no levantamento os dados de sentenças dativas com verbos leves, que formam uma lexia, ou um verbo complexo, com o seu complemento direto. Por outro lado, Lucchesi \& Mello (2009), analisando não só o dialeto de Helvécia, mas três outras comunidades do interior da $\mathrm{Bahia}^{5}$, identificam que, nos casos de lexias formadas por verbos leves mais complementos deverbais, também pode ocorrer a omissão da preposição sem a necessidade de adjacência entre o verbo e o dativo, como no exemplo em (19).

(19) Cê manda pedi um empresti ele. ${ }^{6}$

(Helvécia)

(Lucchesi \& Mello, 2009: 442)

Isso faz com que exista ao menos um contexto em que o dativo pode ocorrer sem preposição, no dialeto de Helvécia, sem estar em adjacência estrita ao verbo, pois a exigência de adjacência entre o complemento direto e o verbo é, de certo modo, mais forte.

Entretanto, é preciso notar que, em todo o corpus levantado e analisado pelos autores, a ordem [ $\left.\mathrm{V}_{\text {leve }} \mathrm{DP}_{\mathrm{TEMA}}(p)+\mathrm{DP}_{\mathrm{DAT}}\right]$, com o complemento deverbal entre o verbo leve o dativo, é a única possível. A inversão entre os complementos não é disponível, como afirmam os próprios autores:

\footnotetext{
${ }^{5}$ A saber, Cinzento, Sapé e Rio de Contas. Cf. Lucchesi, Baxter, Silva \& Figueiredo (2009).

${ }^{6}$ Esse é o único exemplo de omissão da preposição com lexias no corpus de Helvécia, apresentado por Lucchesi \& Mello (2009). Os demais dados são de outras comunidades. Além desses casos, o texto dos autores fala da existência de mais sete dados com omissão da preposição na ordem [V DP $\mathrm{PEMA}_{\mathrm{TE}}+\mathrm{DP}_{\mathrm{DAT}}$ ], mas não há indicação sobre qual a comunidade em que eles ocorrem. Para se verificar o status teórico da omissão da preposição nessas outras comunidades, seria necessária uma análise mais detalhada.
} 
"Além disso, a alta coesão do verbo com o OD, com o qual forma uma única lexia composta, impede a ocorrência da ordem OI-OD”. (Lucchesi \& Mello, 2009, p. 446)

Os exemplos semelhantes a (19), não são, portanto, necessariamente um contraargumento para a generalização de que a omissão da preposição, em Helvécia, só ocorre em adjacência ao verbo, pois essas lexias podem ser consideradas exatamente casos de verbos complexos, formados por uma incorporação entre o verbo e o complemento direto.

É importante apontar que, assim como no dialeto mineiro, a omissão também ocorre em sentenças em que o objeto direto está omitido, como em (20), o que também resulta numa situação de adjacência linear entre dativo e verbo.

(20) a. Acho que num dero eles não.

(Helvécia, Inquérito 03)

b. Eu paguei o japonês.

Entretanto, o status de adjacência entre o dativo e o verbo, nesse tipo de dado, não é claro. A possibilidade de objeto nulo é uma propriedade mais geral do PB, também presente no dialeto de Helvécia (cf. Figueiredo, 2004), não sendo exclusiva das construções dativas com omissão da preposição. ${ }^{7}$ Devido à não-realização do objeto nulo, não podemos saber se a adjacência linear entre o verbo e o dativo também corresponde a uma adjacência estrutural. Em outras palavras, se o objeto nulo for um pronome nulo, por exemplo, ele pode estar estruturalmente antes ou depois do complemento dativo, como em (21).

(21) a. ... num dero ø eles não.

b. ... num dero eles $\boldsymbol{\emptyset}$ não.

Diante da inexistência de dados com omissão da preposição na ordem [V $\mathrm{DP}_{\mathrm{TEMA}} \mathrm{DP}_{\mathrm{DAT}}$ ], Cavalcante \& Barros (2009) consideram plausível que, nesses dados, o objeto nulo não quebra a adjacência entre o verbo e o dativo. Em outras palavras, se o complemento direto nulo estiver efetivamente representado na estrutura sentencial

\footnotetext{
${ }^{7}$ Note-se que a expressão "construções de duplo objeto" perde significado diante de exemplos em que apenas o complemento dativo é realizado.
} 
(digamos, como um pronome nulo ou uma variável (cf. Cyrino, 1997)), nas construções de dativos sem preposição, ele (i.e. o objeto nulo), por hipótese, estará na mesma posição dos objetos realizados em (18), a saber: após o dativo. ${ }^{8}$

Interessa, também, à caracterização das propriedades da omissão da preposição em Helvécia saber se está disponível no dialeto o alçamento do DP dativo para a posição de sujeito em sentenças passivas. Barros (2008) não encontrou dados desse tipo no corpus analisado. Também Lucchesi \& Mello (2009) não identificaram dados desse tipo no corpus expandido com que trabalharam. Entretanto, é difícil chegar à conclusão se isso significa que a passivização do complemento dativo é possível ou não, uma vez que não temos acesso a julgamentos de gramaticalidade dos falantes desse dialeto, além de existirem poucos dados de sentenças passivas no corpus e, de um modo geral, construções passivas serem muito pouco produtivas nesse dialeto, como apontam pesquisas. $^{9}$

Na próxima seção, apresentamos a nossa análise para o fenômeno da omissão da preposição em Helvécia e na Zona da Mata.

\section{Análise: dois tipos de omissão da preposição}

Os dados apresentados nas seções anteriores podem ser assim resumidos:

\begin{tabular}{|l|l|l|l|}
\hline & \multicolumn{1}{|c|}{ Inglês } & \multicolumn{1}{c|}{ Helvécia } & \multicolumn{1}{c|}{ Zona da Mata } \\
\hline Ordem & Apenas em adjacência a V & Apenas em adjacênca a V & Em qualquer ordem \\
\hline $\begin{array}{l}\text { Passivização } \\
\text { do dativo }\end{array}$ & Possível e produtiva & Ausente & Agramatical \\
\hline $\begin{array}{l}\text { Restrição } \\
\text { contextual }\end{array}$ & Não há & Não há & Apenas diante de D ${ }^{\circ}$ s \\
\hline
\end{tabular}

Quadro 1: Propriedades da omissão da preposição em inglês, em Helvécia e na Zona da Mata

\footnotetext{
${ }^{8}$ Outra alternativa é que, mesmo que o objeto nulo ocorra entre o verbo e o dativo, isso não interfere no licenciamento do dativo sem preposição. Essa visão, parece-nos, pressupõe que o fenômeno da omissão requer adjacência linear, mas não estrutural, sendo, em essência, um fenômeno de PF, o que não seria compatível com a ideia de licenciamento alternativo de Caso estrutural.

${ }^{9} \mathrm{O}$ trabalho de Antonino (2003), sobre concordância de gênero em sentenças passivas e predicativas em Helvécia, levanta menos de 18 dados de sentenças passivas em todo o corpus. Não é possível saber o número exato de passivas uma vez que a autora reúne, na sua tabela 1, sentenças com predicados verbais e passivas sob o mesmo rótulo.
} 
O exame do Quadro 1 mostra que o dialeto de Helvécia e o inglês se comportam de modo semelhante em pelo menos dois dos três aspectos considerados, a saber: (i) a omissão da preposição ocorre apenas em casos de adjacência do dativo ao verbo e (ii) não é sensível a nenhum condicionamento categorial quanto à estrutura do constituinte dativo. O dialeto da Zona da Mata se comporta de maneira oposta, exibindo dativos sem preposição em qualquer ordem, mas apresentando uma restrição quanto à estrutura do complemento dativo, que deve iniciar com um elemento que ocupe a posição $\mathrm{D}^{\circ}$.

Com base nessas propriedades, propomos que a omissão da preposição no dialeto de Helvécia é resultado de um processo alternativo de atribuição de Caso estrutural, similar ao que ocorre nas construções de duplo objeto do inglês. Assumimos, em linhas gerais, uma análise como a de Larson (1988), em que o objeto direto recebe Caso inerente diretamente do verbo, enquanto o objeto dativo recebe Caso estrutural acusativo em uma posição estruturalmente mais alta.

Uma questão em aberto é se o DP dativo se move para essa posição casual a partir da posição original de complemento (irmão) de V, como na proposta de Larson (1988), representada anteriormente em (8); ou se o dativo é gerado diretamente em uma posição estruturalmente mais alta que a do complemento direto, a saber, especificador do VP, como em (22).

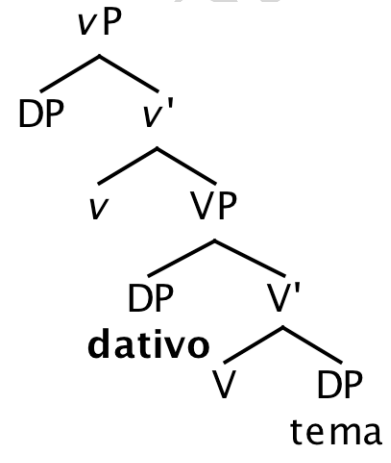

A decisão entre as estruturas em (8) e (22) depende, parcialmente, da posição que o pesquisador adote com relação à UTAHT (Uniform Theta-Role Assignment Hypothesis; cf. Baker, 1988) e a legitimidade de movimentos curtos, no sentido de Abel (2003). A primeira análise tem a vantagem de respeitar a UTAH, por manter a relação de univocidade entre papéis temáticos e posições estruturais, porém tem a desvantagem 
de requerer o movimento do dativo desde a posição de complemento de $\mathrm{V}$ para o especificador da mesma categoria - o movimento não poderia ser para o especificador de $\mathrm{vP}$, pois isso resultaria, em inglês, numa ordem em que o dativo antecede o verbo. ${ }^{10}$

Que fique claro que a implementação técnica específica da análise do caso do inglês e do dialeto de Helvécia não é central para o trabalho. Com relação a esses dois "dialetos", o ponto principal é a identificação dos dados de dativos sem preposição a um processo alternativo de atribuição ou licenciamento de Caso estrutural. O caráter específico de nossa proposta diz respeito ao status do dialeto mineiro.

Retornemos às informações apresentadas no Quadro 1. Já apontamos que o dialeto da Zona da Mata se diferencia do dialeto de Helvécia em dois aspectos e do inglês em três. Diferentemente de Helvécia e do inglês, os dativos podem ocorrer sem a preposição independentemente de estarem em adjacência ao verbo. Por outro lado, a omissão só pode ocorrer quando o complemento dativo corresponde a um núcleo $\mathrm{D}^{\circ}$ ou é iniciado por um — restrição não existente nem em inglês nem em Helvécia.

(23) a. Eu pago minha prima.

(Helvécia)

b. Ele vendia compade Jacó porco gordo.

(24) a. I showed everyone the map.

(inglês)

b. She gave noone a chance.

Consideramos que o que realmente faz do dialeto da Zona da Mata um caso especial é justamente esse segundo requerimento quanto à forma do complemento dativo e não a ordenação livre dos complementos verbais. É preciso notar que o requisito de adjacência entre o verbo e o complemento (dativo) no inglês não é uma característica específica das construções de duplo objeto, mas está relacionada à ausência de movimento do verbo para $\mathrm{T}^{\mathrm{o}}$. Em uma língua como o português, em que se assume que o verbo sai do VP $(=v \mathrm{P})$ para $\mathrm{T}^{\mathrm{o}}$, a adjacência entre o verbo e o dativo pode, em princípio, ser quebrada por algum adjunto (à esquerda) de $v \mathrm{P} / \mathrm{VP}$ ou por um

\footnotetext{
${ }^{10}$ Uma alternativa seria considerar que o movimento para o especificador de $v \mathrm{P}$ ocorre apenas em LF. Outra alternativa seria assumir, mm um modelo que adote a operação de Agree, que o Caso acusativo pode ser atribuído à distância pelo núcleo $v$-zinho sem a necessidade de movimento.
} 
movimento adicional do objeto direto para uma posição mais alta que o dativo (cf. Armelin, 2008).

A possibilidade de que a ordem livre entre dativo e tema seja resultado de algum tipo de movimento do complemento direto já é apresentada por Scher (1996), que deriva a ordem [V $(p)$ DP $\left._{\mathrm{DAT}} \mathrm{DP}_{\mathrm{TEMA}}\right]$, com ou sem preposição, a partir de um processo de topicalização do dativo, por adjunção ao VP (cf. também Armelin (2008) para uma discussão da questão em termos da proposta de Belletti (2002) sobre a periferia funcional do VP).

Diferentemente de Scher (1996) e Armelin (2008), defendemos que a omissão da preposição na Zona da Mata se trata de um processo sintático (ou morfossintático), que resulta na fusão entre a preposição $a$ e o determinante que a segue.

Esse processo de fusão é, em certo sentido, uma generalização do requerimento de fusão que as preposições têm (no português e em outras línguas românicas) com núcleos $\mathrm{D}^{\circ}$ que lhes são complementos, como nos exemplos em (25):

$$
\begin{aligned}
& \text { (25) a. de }+\mathrm{o}=d o \\
& \text { b. de }+ \text { ele }=\text { dele } \\
& \text { c. para }+\mathrm{o}=\text { pro } \\
& \text { d. } \mathrm{em}+\mathrm{o}=n o \\
& \text { e. } \mathrm{em}+\mathrm{ele}=\text { nele } \\
& \text { f. } \mathrm{a}+\mathrm{o}=a o \\
& \text { g. } \mathrm{a}+\mathrm{a}=\grave{a} \\
& \text { h. } \mathrm{a}+\text { aquele }=\text { àquele }
\end{aligned}
$$

Os dados em (25g) e (25h) mostram que mesmo no PB a preposição $a$ acaba sofrendo um tipo de omissão, devido a um processo de crase/fusão com determinantes iniciados pela mesma vogal $a$. As diferenças entre o português urbano (e os outros dialetos que não permitem a omissão, como o próprio português europeu) e o dialeto mineiro podem ser explicadas se assumimos que esse processo de fusão/crase se realiza de modo diferente em cada dialeto.

No caso do português urbano, a fusão entre a preposição e o determinante resulta em apagamento (= crase) da preposição $a$ quando esta fusão ocorre apenas com o artigo 
$a$ e o demonstrativo aquele (e suas flexões). Nos demais casos, temos apenas uma espécie de cliticização do $a$ à forma seguinte, como em (26).

(26) Português urbano (e rural não-mineiro)
a. $\mathrm{a}+\mathrm{o}=a o$
b. $\mathrm{a}+$ ele $=$ a-ele
c. $\mathrm{a}+$ você $=a$-você

No dialeto mineiro, entretanto, o apagamento da preposição ocorre quando a preposição se funde com qualquer determinante, não apenas com aqueles iniciados em $a$, como em (27).

(27) PB da Zona da Mata
a. $\mathrm{a}+\mathrm{o}=o$
b. $\mathrm{a}+$ ele $=$ ele
c. $\mathrm{a}+$ você $=$ você

Um processo de apagamento da preposição $a$ por fusão com um determinante foneticamente não-idêntico é encontrado também no galego (uma língua próxima ao português), em que a contração da preposição a com o artigo masculino $o$ resulta na forma familiar ao ou em $o$ (marcador ortograficamente como $o$ ). Entendemos, então, que o dialeto mineiro se comporta de modo semelhante ao galego por permitir a fusão da preposição $a$ com determinantes que não são foneticamente idênticos.

$$
\begin{aligned}
& \text { (28) a. } \mathrm{a}+\mathrm{o}=a o ; \grave{o} \\
& \text { b. } \mathrm{a}+\mathrm{os}=a o s ; \grave{o s}
\end{aligned}
$$

Defendemos que, no dialeto mineiro, esse apagamento da preposição $a$ sob fusão resulta de um processo de reanálise do ponto da computação em que a fusão deve ocorrer. No PB urbano, a fusão deve ocorrer no componente morfológico, após a derivação sintática. Já no dialeto mineiro, a fusão deve ocorrer já no componente sintático, através do movimento de $\mathrm{D}$ para $\mathrm{P}$.

Descrevemos, a seguir, os dois tipos de fusão com mais detalhes. 
A derivação de um complemento dativo preposicionado como em (29a), no PB urbano, começa com as operações computacionais que formam o DP. Após isso, ocorre merge entre P e DP, conforme (29b).

(29) Português urbano
a. A Maria entregou um presente ao pai.
b. $\left[{ }_{\mathrm{P}} \mathrm{P}[\mathrm{DP} \mathrm{D}[\mathrm{NP} \ldots]]\right] \quad$ (merge sintático entre $\mathrm{P}$ e DP)

A estrutura em (29b) é, então, a que a sintaxe envia para a PF. No componente morfológico, ocorre, então, a inserção de vocabulário, descrita em (29c), de acordo com a hipótese de inserção lexical tardia, da morfologia distribuída cf. (Halle \& Marantz, 1993). Após a inserção, ocorre um merge morfológico entre a preposição e o determinante (para satisfação do caráter afixal daquela). Se o merge é com o determinante $o$, a forma pronunciada é $a o$, como em (27a) e (29a). Se é com o determinante $a$, um processo fonológico posterior reduz a sequência $a a$ para $a$.
(29)
c. [P a [DP o [NP pai ]]]] (inserção de vocabulário)
d. [P [DP a $+_{\mathrm{O}}$ [NP pai ]]]] (merge morfológico de $\mathrm{P}$ ao D)
e. [P [DP ao [NP pai ]]]] (forma a ser pronunciada)

Já no dialeto da Zona da Mata, a derivação de um dativo como (30a) envolve, ainda no componente sintático, uma operação a mais do que no PB urbano: após o merge entre a preposição e o DP dativo, o núcleo $\mathrm{D}$ se move para a posição $\mathrm{P}^{\circ}$, como descrito em (30c).

(30) PB da Zona da Mata
a. A Maria deu um presente o pai / ele.
b. [P P [DP D [NP ... ]]]
(merge sintático entre P e DP)
c. $\left[\mathrm{P}\left[\mathrm{P} \mathrm{D}_{\mathrm{i}} \mathrm{P}\right]\left[\mathrm{DP} \mathrm{B}_{\mathrm{i}}[\mathrm{NP} \ldots].\right]\right]$
(movimento/merge sintático de $\mathrm{D}$

para $\mathrm{P})$

A estrutura em (30c), com o determinante sob o nó $\mathrm{P}^{\mathrm{o}}$ é, então, a que é enviada pela sintaxe à morfologia, o que implica que, sob esse nó, estão presentes, agora, os traços formais de $\mathrm{P}$ e de D (traços- $\phi$, por exemplo). 
Assumindo que o $a$ não expressa conteúdo semântico, mas apenas realiza o traço de Caso dativo (ou oblíquo), há uma competição, no processo de inserção de vocabulário, entre a preposição $a$ e os determinantes (no sentido amplo de artigos ou pronomes nucleares). A preposição $a$ é especificada apenas para o traço oblíquo/dativo, enquanto os determinantes são especificados para os traços- $\phi$ (pessoa, número e gênero).

O princípio de subconjunto (cf. Halle \& Marantz, 1993) diz que, na inserção de vocabulário, vence o item que tiver o maior número de traços dentre o conjunto exigido pelo nó em questão. Uma vez que o nó $\mathrm{P}$ tem tanto o traço de Caso oblíquo quanto os traços- $\phi$, o princípio do subconjunto determina a inserção do determinante (qualquer que seja), como em (31), bloqueando a inserção de $a$, que tem apenas um dos traços requeridos pelo nó $\mathrm{P}$.

$$
\begin{aligned}
& \text { (31) a. [P [P O ] [DP [NP pai ]]] (inserção de vocabulário) } \\
& \text { b. }[\mathrm{P}[\mathrm{P} \text { ele }][\mathrm{DP}]] \quad \text { (inserção de vocabulário) }
\end{aligned}
$$

Dessa forma, consideramos que a omissão da preposição no dialeto da Zona da Mata não é fruto de um processo alternativo de atribuição de Caso ao complemento dativo, ou seja, não envolve uma interação diferente do complemento com a estrutura argumental do VP em que é inserido. A omissão é determinada pela própria estrutura sintática do complemento dativo que, nessa análise, continua sendo formalmente um PP, ou seja, os traços sintáticos da preposição estão presentes na derivação sintática, ao contrário do que uma análise na linha de Larson (1988) assume para o inglês, em que a preposição, atribuidora de Caso, estaria ausente.

A não-realização da preposição, no dialeto mineiro, seria, então, fruto de uma parâmetro relacionado ao movimento (merge) do determinante para o núcleo $\mathrm{P}$, de modo semelhante ao parâmetro de movimento do verbo para $\mathrm{T}^{\mathrm{o}}$, que diferencia línguas como o inglês, de um lado, e as línguas românicas, como o francês, de outro. Nas línguas românicas, assume-se que o movimento do verbo ocorre visivelmente, ainda no componente sintático e que a estrutura enviada a $\mathrm{PF}$ tem o verbo sob o núcleo $\mathrm{T}^{\mathrm{o}}$ que lhe seleciona. Já em inglês, o merge do verbo ao $\mathrm{T}^{\mathrm{o}}$ ocorreria apenas após Spell-Out: em LF, haveria um movimento encoberto do verbo para T; já em PF, haveria um merge do afixo em $\mathrm{T}^{\mathrm{o}}$ ao verbo em $\mathrm{v}^{\mathrm{o}}$, um processo descrito por Chomsky (1955) como affix 
hopping (rebaixamento do afixo) e reinterpretado como um merge morfológico por Hale \& Marantz (1993).

A ideia é que, com relação ao merge entre $\mathrm{D}^{\mathrm{o}}$ e $\mathrm{P}^{\mathrm{o}}$, o dialeto mineiro se comporta como as línguas românicas em relação a $\mathrm{V}^{\mathrm{o}}$ e $\mathrm{T}^{\mathrm{o}}$, e o $\mathrm{PB}$ urbano se comporta como o inglês.

\section{Conclusão}

Em resumo, defendemos aqui que o processo de omissão da preposição dos complementos dativos em Helvécia deve ser analisada como mais um caso do já bem documentado fenômeno das construções de duplo objeto, em que a omissão é estruturalmente condicionada, por ser resultado de um processo alternativo de licenciamento de Caso, em que o dativo deixa de receber Caso da preposição, para receber diretamente do verbo ou $v$-zinho, como no inglês.

Já no dialeto da Zona da Mata, a omissão é resultado de uma reanálise do requerimento, existente no $\mathrm{PB}$, de fusão das preposições aos determinantes. De modo mais específico, as propriedades afixais da preposição $a$ são satisfeitas antes da forma morfológica (ou PF) na Zona da Mata, ainda no componente sintático, através do movimento do determinante para o núcleo P. Esse movimento tem como resultado o que pode ser caracterizado ou como fusão completa da preposição $a$ com o determinante ou como bloqueio da inserção lexical da preposição, a depender se adotamos um sistema de inserção lexical tardia ou não.

Essa análise trata as diferenças entre o PB da Zona da Mata e o português urbano como resultado de um parâmetro de movimento/merge entre núcleos em relação de ccomando, semelhante ao que é assumido para o movimento aberto ou encoberto do verbo para $\mathrm{T}^{\mathrm{o}}$.

\section{Referências}

ANTONINO, Vívian. . A variação da concordância de gênero numa comunidade rural afro-brasileira. Comunicação apresentada no IV Seminário de Pesquisa e PósGraduação e XXII Seminário Estudantil de Pesquisa. Salvador : UFBA, 2003. 
ABEL, Klaus. Successive Cyclicity, Anti-locality and Adposition Stranding. Tese de Doutorado. University of Connecticut, 2003.

ARMELIN, Paula Roberta Gabbai. Sentenças bitransitivas do português brasileiro revisitadas à luz da cartografia estrutural do IP. Comunicação apresentada no XVI Simpósio Internacional de Iniciação Científica (SIICUSP), 2008.

BARROS, Isis J. F. A variação nas construções dativas no dialeto de Helvécia (BA). Lauro de Freitas (BA): UNIME. Trabalho de Conclusão de Curso, 2008.

BELLETTI, Adriana. Aspects of the low IP area. In.: RIZZI, Luigi. (org). The structure of IP and CP. The Cartography of Syntactic Structure. vol. 2. Oxford University Press, 2002.

CAVALCANTE, Rerisson. Complementos dativos sem preposição no dialeto mineiro. ReVEL, vol. 7, n. 12. [www.revel.inf.br], 2009.

CAVALCANTE, Rerisson; BARROS, Isis. Complementos dativos sem preposição no dialeto da Zona da Mata (MG) e de Helvécia (BA). Comunicação apresentada no I ROSAE: Congresso Internacional de Linguística Histórica, Salvador, junho de 2009. (Disponível em http://bit.ly/mlp286 )

CHOMSKY, Noam. Aspects of the Theory of Syntax. Cambridge, MA: MIT Press, 1965. CHOMSKY, Noam. The Minimalist Program. Cambridge, MA: MIT Press (Current Studies in Linguistics 28), 1995.

CHOMSKY, Noam. Minimalist inquiries: the framework. MARTIN, R.; MICHAELS, D.; URIAGEREKA, J. (eds.). Step by step: Essays on Minimalist Syntax in Honor of Howard Lasnik. Cambridge, MA: MIT Press, 2000. p. 81-155.

CYRINO, Sonia Maria Lazzarini. O Objeto Nulo no Português do Brasil: um estudo sintático-diacrônico. Londrina: UEL, 1997.

FIGUEIREDO, Cristina. O objeto direto anafórico no dialeto rural afro-brasileiro. Universidade Federal da Bahia. Dissertação de mestrado, 2004.

HALLE, Morris; MARANTZ, Alec. Distributed morphology and the pieces of inflection. In: HALE, K.; KEYSER, S. J. (eds). The View from Building 20: Essays in Linguistics in Honor of Sylvain Bromberger. Cambridge, Mass.: MIT Press. 1993. p. 111-176. 
LARSON, Richard K.. On the double object construction. Linguistic Inquiry 19, Cambrigde, Mass, 1988. p. 335-391.

LONGOBARDI, Giuseppe. Reference and proper names: a theory of movement in syntax and LF. Linguistic Inquiry, Cambridge, Mass, v. 25, n. 4, 1994. p. 609-665.

LUCCHESI, Dante; BAXTER, Alan; SILVA, Jorge Augusto Alves da; FIGUEIREDO, Silva. O português afro-brasileiro: as comunidades analisadas. In: LUCCHESI, Dante; BAXTER, Alan; RIBEIRO, Ilza. (Orgs). O português afro-brasileiro. Salvador: EDUFBA, 2009. p. 75-100.

LUCCHESI, Dante; MELLO, Camilia. A alternância dativa. In: LUCCHESI, Dante; BAXTER, Alan; RIBEIRO, Ilza. (Orgs). O português afro-brasileiro. Salvador: EDUFBA, 2009. p. 427-456.

LUCCHESI, Dante. As duas grandes vertentes da história sociolinguística brasileira. DELTA, São Paulo, v. 17, n. 1., 2001. p. 97-130.

SCHER, Ana Paula. (1996). As construções com dois complementos no inglês e no português do Brasil: um estudo sintático comparativo. Dissertação de mestrado. Campinas (SP): Unicamp.

TORRES MORAIS, Maria Aparecida C. R.; BERLINCK, Rosane A. (2006). A caracterização do objeto indireto no português: aspectos sincrônicos e diacrônicos. In: LOBO, Tânia; RIBEIRO, Ilza; CARNEIRO, Zenaide; ALMEIDA, Normal. (orgs). Para a história do português brasileiro. Vol. VI: Novos dados, novas análises. Tomo I. Salvador: Edufba.

TORRES MORAIS, Maria Aparecida C. R. (2007). Os dativos. Tese de Livre Docência, São Paulo: Universidade de São Paulo.

Artigo recebido em: 31.03 .2012

Artigo aprovado em: 02.04.2012 